\title{
SEISMIC ANALYSIS OF REINFORCED CONCRETE MODIFIED WITH GLASS AND BAMBOO HYBRID FIBERS
}

\author{
Kavin $\mathbf{S}^{1}$ \\ ${ }^{1}$ Srm University, \\ kavinsri17@gmail.com
}

\begin{abstract}
The aim of this study is first to develop hybrid fibre reinforced concrete (HFRC) and then to characterize and quantify the benefits obtained by the concept of hybridization. Hybrid composites were cast using two fibres namely Glass and Bamboo of different fibre proportions i.e., $1 \%, 1.5 \%$ and $2 \%$ in M35 grade of mix. Compressive test and split tensile strength were performed and results were extensively analyzed to associate with above fiber combinations. The dynamic properties are further analyzed for the optimum percentage of hybrid fibres using ETABS. The reinforced beams of a G+4 residential building is replaced with the optimum dosage of hybrid fibres and analyzed under seismic loads. It is concluded that the overall displacement of the structure is less when compared with conventional reinforced structure.
\end{abstract}

Keywords: glass,bamboo,ETABS

\section{INTRODUCTION}

The damage to buildings due to dynamic loads caused by natural disasters like earthquakes as well as man-made disasters like blasts have been on the rise recently. Hence it has become mandatory to design buildings which are seismic and blast resistant. Concrete is the most commonly used building material though it exhibits brittle nature. Its poor performance in tension and flexure had led to using steel bars.But steel has its own associated drawbacks like cost, higher self-weight, and proneness to corrosion. Owing to such limitations, the usage of synthetic fibres like glass steel and aramid fibres have come to the fore in the past few decades.

Fibres have lesser weight, impart more ductility and help in arresting the micro cracks more effectively.But synthetic fibres have their associated problems of high cost and nonbiodegradable nature which have an adverse effect on the environment. These disadvantages of synthetic fibres have raised the necessity for more environment friendly solutions and bio or natural fibres are a potential choice. But bio fibres seem to have comparatively lesser mechanical properties like tensile strength and toughness. Hence it is necessary to combine both synthetic fibres and bio fibres forming a hybrid that derives maximum benefits from each of them. In this project, the optimum content of bio fibre (bamboo) and synthetic fibre (glass) will be found and the mechanical properties of such a HFRC is determined. The performance of a G+4 structure made with such a HFRC and subjected to dynamic loads of seismic load and blast load will be studied using ETABS software package

\section{II.HYBRID FIBRES REINFORCED CONCERTE}

A composite can be termed as hybrid, if two or more types of fibres are rationally combined in a common matrix to produce a composite that derives benefits from each of the individual fibres and exhibits a synergetic response. According to Benthur and Mindess the advantages of hybrid fibre systems can be listed as follows

- To provide a system in which one type of fiber, which is stronger and stiffer, improves the first crack stress and the ultimate strength, and the second type of fiber, which is more flexible, and ductile leads to improved toughness and strain in the post-cracking zone.

- To provide hybrid reinforcement in which one type of fiber is smaller, so that it bridges the micro cracks of which growth can be controlled. This leads to a higher tensile strength of the composite. The second type of fiber is larger, so that it arrests the propagating macro cracks and can substantially improve the toughness of the composite.

To provide a hybrid reinforcement, in which the durability of fiber types is different. The presence of the durable fiber can increase the strength and/or toughness relation after age while the other type is to guarantee the short-term performance during transportation and installation of the composite elements. The combination of different types of fibres to optimize the performance in the hardened state, with respect to strength and toughness, has been studied by various researchers, using asbestos, carbon, and steel to achieve strength, and polypropylene and polyethylene to improve toughness. But very scarce amount of work has been reported in the area of bio-synthetic hybrid fibres. 


\section{A. OBJECTIVES}

- To determine the compatibility of bio and synthetic fibers by finding out the optimum content

- To estimate the increase in ductility and energy absorption by using bio-synthetic hybrid fibres (glass and bamboo) in concrete beams.

- To carry out the dynamic analysis and check the performance of a structure (made of such a HFRC) subjected to seismic load.

\section{III.LITERATURE REVIEW}

Adriana Ionescu, Madalina Calbureanu, Mihai Negruet (2013) simulated static and dynamic analysis on seismic behavior of the building structure using ANSYS software. They have carried out seismic stimulation using the static equivalent force method and the modal spectral analysis method. The study was made in order to determine which type of analysis is more convenient and easier to be applied in ANSYS program. They concluded that the modal spectral analysis is more convenient though the results of both methods are very similar.

Ngo et al (2007) had come up with a comprehensive overview of the effects of explosion on structures. An explanation of the nature of explosions and the mechanism of blast waves in free air was given. This paper also introduces different methods to estimate blast loads and structural response. They felt that, for high-risks facilities such as public and commercial tall buildings, design considerations against extreme events (bomb blast, high velocity impact) are very important. They recommended that guidelines on abnormal load cases and provisions on progressive collapse prevention should be improved. They also felt that the requirements on ductility levels also help improve the building performance under severe load conditions.

Ojaswi Panda et al (2012)fabricated a new class of epoxy based hybrid composites reinforced with randomly oriented short glass fibres and bamboo fibres. They carried out evaluation of mechanical properties such as tensile strength, flexural strength and micro hardness for these composites. Three different relative fibre proportions were adopted, and in each the length of the fibre was varied from $0.5 \mathrm{~cm}$ to $1.5 \mathrm{~cm}$. Theyconcluded that the mechanical properties of the composites slightly increase in all the three different relative fibre proportions irrespective of fibre lengths. But the maximum tensile and flexural strength among all the composites was $24.41 \mathrm{MPa}$ for $0.5 \mathrm{~cm}$ fibre length with relatively more glass fibre content.

Venkatasubrmani et al (2014) studied the performance of hybrid fibre beams under cyclic loading. They had carried out observation on first crack and ultimate strength of conventional concrete beams and hybrid fibre beams. They concluded that in hybrid beams the ultimate load caring capacity increases by $26 \%$ than conventional concrete beam. They also found that cracks are closely spaced and also crack width is very less when compared to conventional concrete.

\section{A. REVIEW OF LITERATURE}

Mechanical properties of the HFRC composites like the ultimate tensile and flexural strength increase and they show better performance than conventional concrete.For synthetic HFRC beams, ultimate load caring capacity increases by $26 \%$ than conventional concrete beam. When fibres are used, cracks are closely spaced and also crack width is very less when compared to conventional concrete. The method of modal spectral analysis is more convenient to simulate static and dynamic analysis on seismic behaviour of the building structure using ANSYS software.It is recommend to use guidelines for abnormal load cases and better ductility levels shown by FRC help to improve the building performance under adverse load conditions.

\section{$B$. NEED FOR THE RESEARCH}

In recent years the frequency of natural as well as man-made calamities like earthquake have increased alarmingly pushing us to go for more seismic resistant building design.In view of this, materials modified with synthetic fibres such as glass offer the advantages of higher stiffness and strength to weight ratio as compared to conventional construction materials. But they have high initial costs and adverse environmental impact. A potential substitute is the class of natural fibres which are available at low cost, light weight and areenvironment friendly. Among many of the natural fibres, bamboo fibre is one of the most promising one, because of its short growth cycle and high availability.But bamboo fibres have inferior mechanical properties than glass fibres. For this reason it is necessary to use both bio and synthetic fibres in unison and hence it is necessary to estimate the relative optimum content of glass and bamboo fibres for deriving maximum benefit from both.

\section{IV.MATERIALS}

\section{A) Cement}

The cement used for this study is Portland Pozzolanic Cement is conforming to Indian Standard IS 12269 - 1987 of grade 53

\section{B) Fine Aggregate}

The sand is used as fine aggregate and it is collected from nearby area (zone-II). The sand has been sieved using 4.75 $\mathrm{mm}$ sieve

\section{C) Coarse Aggregate}

The coarse aggregate is choosen by shape as per IS 2386 (Part I) 1963, surface texture characteritics of aggregate is classified as in IS $383-1970$. 


\section{D) Fibres}

Table 1 : Fibre Properties

\begin{tabular}{|c|c|c|}
\hline Properties & Glass & Bamboo \\
\hline Aspect ratio & 50 & 50 \\
\hline $\begin{array}{c}\text { Young's } \\
\text { modulus(Gpa) }\end{array}$ & 80 & $33-40$ \\
\hline $\begin{array}{c}\text { Tensile } \\
\text { strength (Mpa) }\end{array}$ & 2000 & $350-500$ \\
\hline
\end{tabular}

E) Specimen details

- Cube of size 150 X 150 X $150 \mathrm{~mm}$ are used for making both conventional concrete and hybrid fibre reinforced concrete Specimens.

CYLINDERS OF 150MM DIAMETER AND 300MM HEIGHT ARE USED FOR MAKING BOTHCONVENTIONAL CONCRETE AND HYBRID FIBRE REINFORCED CONCRETE SPECIMENS.

\section{EXPERIMENTAL STUDY}

\section{A. COMPRESSION TEST OF CUBES}

Compression strength for conventional concrete $(28$ days $)=$ $44.25 \mathrm{~N} / \mathrm{mm}^{2}$

Compression strength of M35 grade concrete for 1\%, 1.5\% and $2 \%$ dosage of HFRC is shown in table 2

Table 2: Compression Strength of M35 grade concrete for 28 days

\begin{tabular}{|c|c|c|c|}
\hline \multirow{3}{*}{$\begin{array}{c}\text { Percentage of } \\
\text { fibre }\end{array}$} & \multicolumn{3}{|c|}{ 28 days } \\
& \multicolumn{3}{|c|}{ Compressive strength } \\
$\left(\mathbf{N} / \mathbf{m m}^{2}\right)$ \\
\cline { 2 - 4 }
\end{tabular}

\section{B. SPLIT TENSILE TEST OF CYLINDER}

Split tensile strength for conventional concrete (28 days) $=3.8$ $\mathrm{N} / \mathrm{mm}^{2}$

Split tensile test of M35 grade concrete for 1\% dosage of HFRC is shown in table 3
Table 3: Split Tensile Strength of concrete for 28 days

\begin{tabular}{|c|c|c|c|}
\hline \multirow{2}{*}{ Percentage } & \multicolumn{3}{|c|}{ Tensile Strength N/mm } \\
\cline { 2 - 4 } & \multicolumn{3}{|c|}{ Dosage of fibre } \\
\cline { 2 - 4 } & $\begin{array}{c}\text { Glass- } \\
\text { bamboo } \\
(\mathbf{3 0 - 7 0 )}\end{array}$ & $\begin{array}{c}\text { Glass - } \\
\text { bamboo } \\
(\mathbf{5 0 - 5 0 )}\end{array}$ & $\begin{array}{c}\text { Glass- } \\
\text { bamboo } \\
(\mathbf{7 0 - 3 0 )}\end{array}$ \\
\hline $1 \%$ & 4.38 & 4.74 & 4.87 \\
\hline
\end{tabular}

\section{COMPARISON OF \\ STRENGTH}

COMPRESSIVE

This graph shows the comparison Compression strength of Conventional concrete and various dosages of fibres is shown in figure 1.

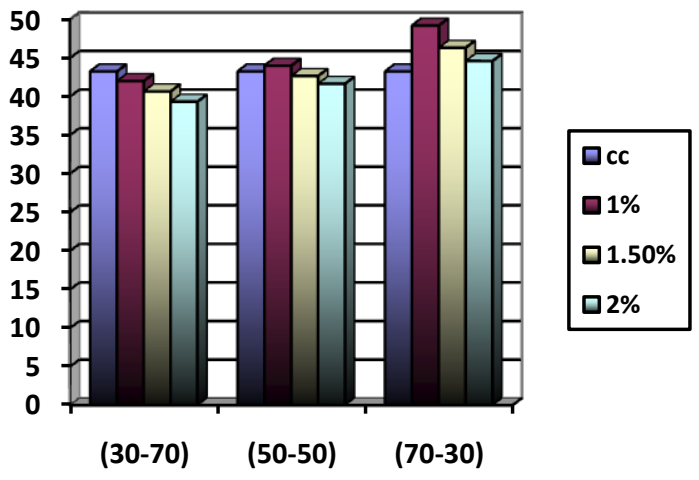

Fig 1 Comparison of 28 days compression strength of Conventional Concrete and 1\%, $1.5 \%$ and $2 \%$ of hybrid fibre

\section{COMPARISON OF SPLIT TENSILE STRENGTH}

This Graph shows the comparison of 28 days split tensile strength of conventional concrete and $1 \%$ of hybrid fibre is shown figure 2 .

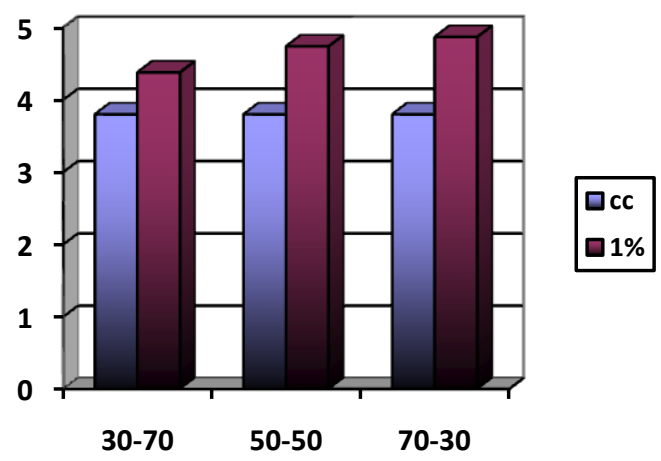

Fig 2 Comparison of 28 days Split Tensile strength of Conventional Concrete and 1\% of hybrid Fibre 


\section{SESMIC ANYALSIS}

\section{A. PLAN}

A plan of four storey reinforced concrete (RC) frame structure is considered for modeling and analysis using ETABS
Beam sizes
$=250 \times 300 \mathrm{~mm}$
Storey Height
$=3.08 \mathrm{~m}$.
Columns sizes
$=350 \times 350 \mathrm{~mm}$
Live Load
$=2 \mathrm{kN} / \mathrm{m} 2$
Slab thickness
$=120 \mathrm{~mm}$
Floor Finish Load
$=1 \mathrm{kN} / \mathrm{m}$

Concrete grade M35

Steel Fe500

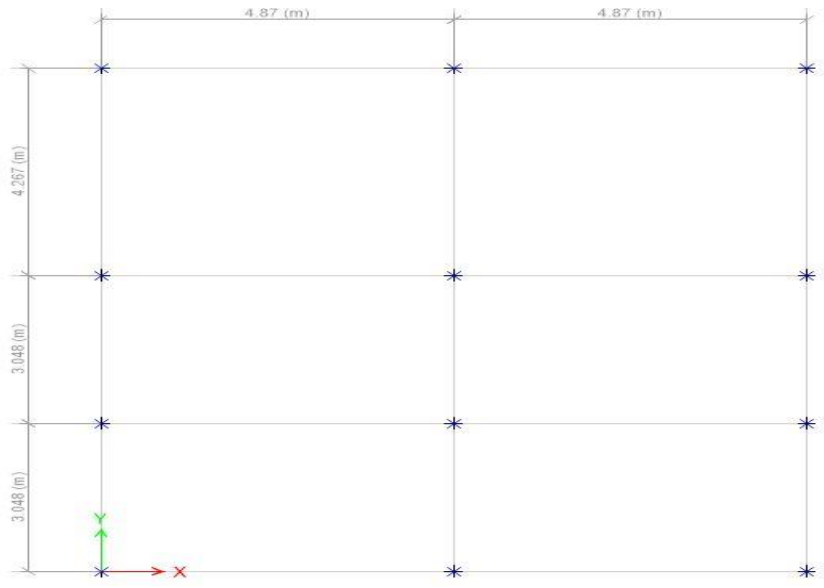

Fig 3 Floor Plan

\section{B. LOADING}

Table 4: Loading Type

\begin{tabular}{|l|l|l|}
\hline LOAD NAME & TYPE & VALUE \\
\hline Dead (DL) & Dead load & $18.596 \mathrm{kN} / \mathrm{m}$ \\
\hline Live (LL) & Live load & $2 \mathrm{kN} / \mathrm{m} 2$ \\
\hline Roof & Dead load & $5.6 \mathrm{kN} / \mathrm{m}$ \\
\hline Roof live & Roof live & $1.5 \mathrm{kN} / \mathrm{m} 2$ \\
\hline $\begin{array}{l}\text { Load combination } \\
\text { Given as per IS1893:part I }\end{array}$ \\
\hline
\end{tabular}

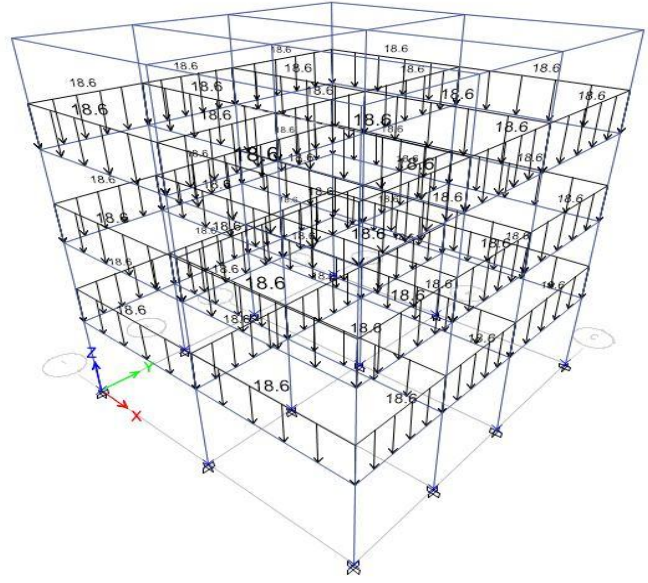

Fig 4 Application of dead load

\section{A. Response Spectrum}

Earthquake response spectrum is the most popular tool in the seismic analysis of structures. There are computational advantages in using the response spectrum method of seismic analysis for prediction of displacements and member forces in structural systems. This method of analysis measures the contribution from each natural mode of vibration to indicate the maximum seismic response of the structure. It provides insight into dynamic behavior by measuring pseudo-spectral acceleration, velocity, or displacement as a function of structural period for a given level of damping.

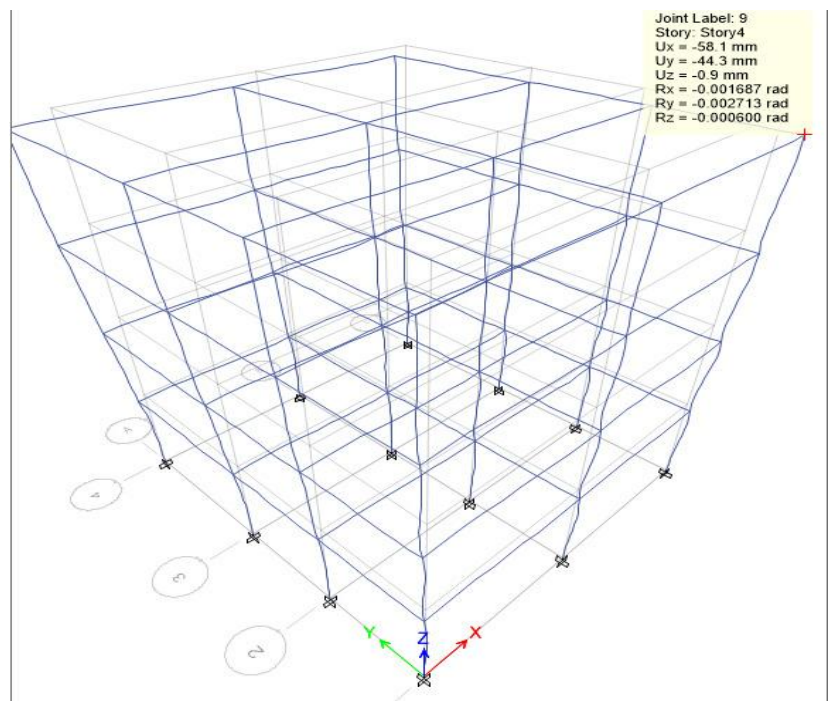

Fig 5 Response spectrum analysis of $\mathrm{RC}$ structure

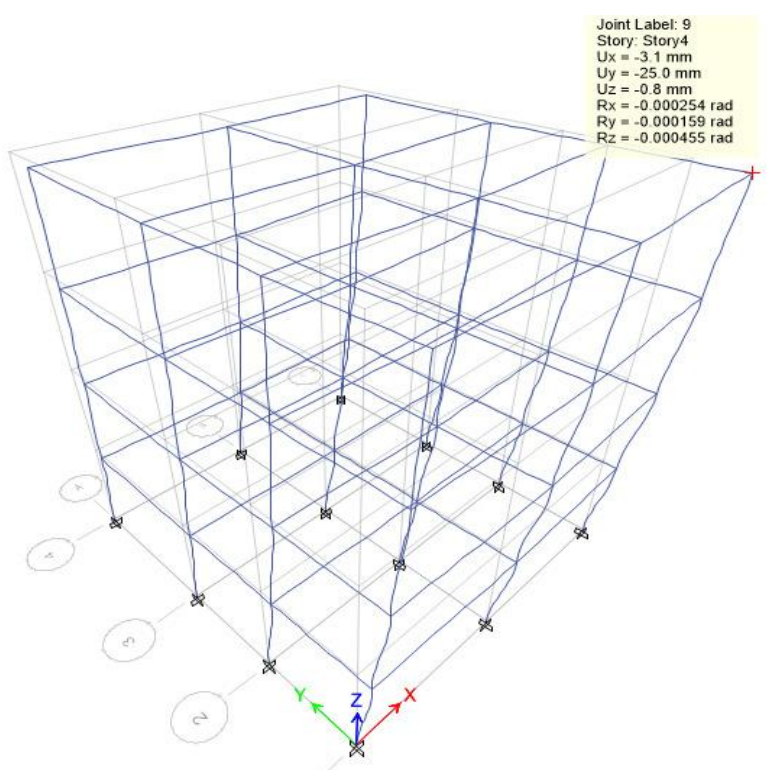

Fig 6 response spectrum analysis of HFRC structure 


\section{COMPRISION OF RESULTS}

Total deformation value of the both structure is listed in Table 5

Table 5: comparison of conventional concrete and hybrid fibre concrete

\begin{tabular}{|c|c|c|c|}
\hline \multirow[t]{2}{*}{ Туре } & \multicolumn{3}{|c|}{$\begin{array}{l}\text { Deformation } \\
\text { (mm) }\end{array}$} \\
\hline & UX & $\mathbf{U Y}$ & $\mathbf{U Z}$ \\
\hline $\mathrm{RCC}$ & 58 & 44.3 & 0.9 \\
\hline HFRC & 31 & 24 & 0.4 \\
\hline
\end{tabular}

\section{CONCLUSION}

1. The experimental investigation on the mechanical behavior of HFRC (glass and bamboo fibres) for various dosage of fibre was conducted. Properties such as the compression strength and Tensile strength were evaluated from experiments. The experiments lead to the conclusions that with $1 \%$ addition of hybrid fibre increases the compression strength by $10 \%$ and tensile strength by $22 \%$ than conventional concrete

2. Seismic Response spectrum analysis is carried outfor $\mathrm{G}+$ 4 structures by modifying RCC beams with HRFC beams in ETABS. Total deformation is studied for both RCC and HFRC structures. It concludes that Modified HFRC structure shows reduced deformation than RCC structure.

\section{REFERENCE}

[1] Adriana Ionescu, Madalina Calbureanu, Mihai Negruet (2013) 'Static and dynamic simulation in the seismic behaviour of a building structure using ANSYS program' international journal of mechanics

[2] L.Dahmani et al(2010)'Crack Identification in Reinforced Concrete Beams Using ANSYS Software' Mouloud Mammeri University, Tizi-Ouzou, Algeria

[3] Jing Ji, Wenfu Zhang, Wenyan Zhao 'Research of Seismic Testing and Dynamic Character of High-rise Building Structure Based on ANSYS' Volume6,Number8,May 2012 doi:10.4156/jdcta.vol6.issue8.8

[4] Komal Chawla and Bharti Tekwani 'Glass Fibre Reinforced Concrete'

[5] T. Ngo et al (2007)' Blast Loading and Blast Effects on Structures' EJSE Special Issue: Loading on Structures (2007)

[6] Ojaswi Panda et al (2012) 'A study on the effect of fiber parameters on the mechanical behaviour of bambooglass fiber reinforced epoxy based hybrid composites' department of mechanical engineering national institute of technology

[7] C. P. Pantelides, T. T. Garfield 'Behavior of Concrete Panels Reinforced with Synthetic Fibers, Mild Steel, and GFRP Composites Subjected to Blasts' Structures 2012 Congress

[8] Shende.A.M, Pande.A.M 'Comparative study on Steel fibre reinforced cum control concrete under flexural and deflection' international journal of applied engineering research, dindigul Volume 1, No 4, 2011

[9] Dr.R.venkatasubrmani et al(2014)'Study on Performance of HFRC flexural member under cyclic loading' International Journal of Science, Engineering and Technology Research (IJSETR), Volume 3, Issue 5, May 2014. 